\title{
A comparison of surface features on submerged and non- submerged bone using scanning electron microscopy
}

\author{
R. DeBattista ${ }^{11 *}$, T.J.U. Thompson ${ }^{1}$, C.E.L. Thompson ${ }^{2}$ and R.L.Gowland ${ }^{3}$
}

${ }^{1}$ School of Science and Engineering, Teesside University, Middlesbrough, Cleveland, TS1 3BA, United Kingdom.

${ }^{2}$ School of Ocean and Earth Science, University of Southampton, National Oceanography Centre, Southampton, University of Southampton Waterfront campus, European Way, Southampton, SO14 3ZH.

${ }^{3}$ Department of Archaeology, Durham University, South Road, Durham, DH1 3LE, UK

\footnotetext{
' Heritage Malta - Head Office, Diagnostic Science Laboratories, Ex-Royal Naval Hospital, Marina Street, Bighi, Kalkara, KKR9933, Malta.

*Corresponding author. Email: roslyndebattista@gmail.com (R. DeBattista)
} 
*Blinded Manuscript (WITHOUT Author Details)

Click here to view linked References

A comparison of surface features on submerged and nonsubmerged bone using scanning electron microscopy 


\section{Abstract}

Skeletal remains are excellent sources of information regarding the deceased individual and the taphonomic history of their body. However, the accuracy of this information is governed by our ability to interpret features on the surface of a bone. Little research in this respect has been carried out on remains found in aquatic environments. This study compares damage features created on the surface of modern and archaeological bone found in a seawater environment, to surface features present on unmodified bone, archaeological bone, pathological bone and burned bone. Results show that no similarities with regard to surface pores were identified between submerged modern bone and archaeological, pathological and burned bone. Similarities were seen between submerged and dry archaeological bones. Thus it is argued that the misinterpretation of the taphonomic history of isolated bones recovered from bodies of water should be avoidable in the forensic context.

\section{Keywords}

Forensic anthropology, taphonomy, bone, sediment transport, aquatic environment, Scanning Electron Microscopy. 


\section{Introduction}

Despite the vast expanses of water surrounding us and the regularity with which human remains are recovered from them, very little research has been conducted on the taphonomic changes undergone by bone as a consequence of prolonged submergence. When human remains are introduced into any aquatic environment, the nature and type of remains as well as the unique conditions of that particular environment will determine specific damage mechanisms, movement of the remains, decomposition and skeletonization ${ }^{[1]}$. This combination of variables means that it is often difficult to successfully interpret the conditions surrounding the circumstance of death and time-since-death within the medico-legal context. This research therefore aims to provide some much needed information on the likely impact of damage from mobile sediments on the interpretation of bone surface features.

Of the previously published work on human remains in bodies of water, most have described general trends with regard to soft tissue decomposition within an aquatic environment ${ }^{[2,3,4,5]}$. A decomposing body within water can go through the standard phases of putrefication, saponification (adipocere formation) and mummification $^{[6,7,2,3,8]}$. Insect infestation and bird scavenging may also occur on the aerially exposed body parts, ${ }^{[3]}$ whereas fish, crustaceans and other types of aquatic organisms will scavenge on the submerged remains ${ }^{[4]}$. This will increase the rate of decomposition and has an effect on the time taken for skeletal elements to be exposed and become available for change themselves.

Little is understood regarding the taphonomic processes affecting the skeletonized body within water. Some work has demonstrated the issues surrounding element dispersal across a body of water, particularly in rivers ${ }^{[9]}$. Unfortunately, as is often the case with forensic taphonomic research, there are few highly controlled experimental studies which can be used to garner a base-line for changes from which conditions within the forensic context can be inferred. Thompson et al. ${ }^{[10]}$ subjected both modern and archaeological bone to bombardment with sediment grains in an annular flume so as to determine the relationship between sediment transport patterns and damage to bone surfaces. Both the bone types were subjected to varying mobile sediment bed conditions in a freshwater environment, for a range of time intervals. It 
was concluded that the degree of wear was dependent on the bone type, exposure time, sediment particle transport mode and sediment type. This has interesting implications regarding the better understanding and interpretation of the morphological degradation of bone. One issue still of great concern is whether abrasion marks evident on remains exposed to sediment bombardment, rock, silt and other types of debris are identifiable as such, or if they may be confused with similar surface changes resulting from a number of other phenomena which can create new pores on the surface of bone (e.g. normaldiagenesis, disease or burning). This has important implications for the creation of osteological profiles and the interpretation of skeletal remains.

Therefore, this paper focuses on the comparison of damage caused to bone surfaces from sediment bombardment to changes that have resulted from other known causes.

\section{Materials and Methods}

In order to carry out this investigation, an experimental approach was adopted. Since the aim of this research is to ascertain the similarities and differences between abrasion marks created by bombardment and those surface marks created by nonaquatic means, a number of bones were used for morphological comparisons. In addition to the submerged bones, a range of archaeological, burned and pathological bones were examined. Specific samples were chosen with abnormal surface morphology and therefore more likely to be confused with abrasive marks in the field. Table 1 contains details of the samples used.

Table1. Detailed description of the samples and exposure parameters.

\section{Submerged Samples}

Modern and archaeological bones were used to investigate the effects brought about by submersion in an aquatic environment. The modern bones were adult sheep femora, while the archaeological bones used were human femora. Dry controls were retained for each bone type. 
Full details for the process of bombardment are given in Thompson et al. ${ }^{[10]}$, but to summarise, the bones were placed in a small annular flume consisting of seawater and sand-sized sediment. The sediment used was a well-sorted, sub-rounded, fine grained white quartz beach sand with a median diameter of $200 \mu \mathrm{m}$. A total of 650 grams of sand were placed in the mini flume, amounting to a one centimetre high uniform bed. Bone samples were added and subjected to mobile sediment bed conditions. Three different flow velocities were chosen so as to subject the bone to different transport modes (bedload, saltation and suspension), while the bones remained stationary during the experiment. The three velocities used were $0.34 \mathrm{~ms}^{-1}$, $0.37 \mathrm{~ms}^{-1}$ and $0.44 \mathrm{~ms}^{-1}$ and a range of exposure time intervals (0-120 hours) was used for the investigation.

An additional four modern adult sheep bones were sectioned and exposed to bombardment from a largersediment and freshwater. One of these bones was used as a control and kept out of the water for the duration of the experimentation period. The other three bones where submerged and bombarded using medium quartz sand grains of size $600 \mu \mathrm{m}$ at a current velocity of $0.4 \mathrm{~ms}^{-1}$. The three bones were submerged in this environment for different time periods, namely 6, 8 and 13 hours.

\section{Non-submerged (Comparative) Samples}

\section{Weathered samples (Archaeological)}

Archaeological bone is usually known to be fragile and brittle. Robinson ${ }^{[11]}$ states that this is due to the loss of strength and elasticity as a result of the degradation of the organic and inorganic components of the bone. The degree of degradation varies as a result of the interactions between the bone and the surrounding sediment and environment in which it is buried ${ }^{[12]}$. Byres ${ }^{[13]}$ concluded that with time, buried bone goes through various changes due to both intrinsic characteristics of the bone (e.g. size of the bone, age at death of the individual who died) and extrinsic factors within the environment (e.g. presence of a coffin, soil pH, physical disturbance). Both of these can affect the morphological texture of the bone. When a bone is freshly introduced into soil, it would primarily have a smooth surface, however with 
environmental conditions, such as exposure to soil acids which slowly erode the bone, the bone's surface is altered causing morphological changes such as pitting. Eight archaeological bones were examined in total.

\section{Pathological Samples (Archaeological)}

Certain types of disease may manifest on the skeleton, though it tends only to be chronic conditions that result in skeletal lesions. There are a plethora of diseases which manifest themselves as pitting or porosity on pathological bone, which may potentially be confused with taphonomic alterations These include those related to infections such as periostitis, osteomyelitis, tuberculosis, leprosy and syphilis; reticuloendothelial diseases such as Gaucher's disease; hematopoietic diseases such as porotic hyperostosis; metabolic diseases such as osteoporosis and rickets; some endocrine diseases such as hyperparathyroidism; tumors, and; some types of degenerative joint disease such as osteoarthritis, rheumatoid arthritis and psoriatic athritis $^{[14,145]}$. Here we examined examples of osteoarthritis and periosteal new bone growth, since both are common skeletal conditions which modify the surface of the bone. They are referred to here as pathological bone.

\section{Burned Samples (Modern)}

When bone burns, it goes through several processes causing it to undergo various morphological changes which would be evident from its surface. Four stages of heatinduced transformation are evident - dehydration, decomposition, inversion and fusion $^{[16,17]}$. Significant changes to surface porosity and quality occur in the first two stages as the water and organic material are lost from the bone at low temperatures and then again at higher temperatures in the final fusion stage as the inorganic phase remodels ${ }^{[17,18]}$. In this study, two modern sheep bones were used to investigate the general morphology of the bone after being exposed to low $\left(500^{\circ} \mathrm{C}\right)$ and high $\left(900^{\circ} \mathrm{C}\right)$ burning intensities for 45 minutes.

\section{Morphological Examination}


The microscopic examination for this investigation was carried out using a Hitachi S$3400 \mathrm{~N}$ environmental scanning electron microscope. The variable pressure setting was used to eliminate the need to carbon or gold coat the samples, as would otherwise have been needed to prevent charging of the sample. Backscatter electron detection was used to obtain morphological information. The magnifications chosen to examine bone morphology were X10, X50 and X100. At each magnification, micrographs were taken to document findings. Using such magnifications, it was possible to outline the general morphology of the bone and then closely examine any areas of interest. Measurements of the abrasion marks, pores or pitting present on the bone were also taken using this instrument. This was done so as to be able to compare pore and surface feature sizes.

\section{Results}

\section{Submerged Samples}

The morphological examinations performed on the bones subjected to bombardment in an aquatic environment are shown in Fig. 1. The damage to the surface of the bones resulting from sediment bombardment is consistent with that found in Thompson et al. ${ }^{[10]}$. It was noted that the type of water had no effect on features observed, and that any variations in the size of the abrasions could be attributed to the size of the grains in the water.

Fig. 1.The general appearance of the morphological features present on the modern and archaeological bones after being subjected to an aquatic environment.

\section{Non-submerged (Comparative) Samples}

The morphology of the dry archaeological bones appeared to be well preserved with minor cracking features (Fig. 2). The condition of the external periosteal surface was good, with the majority of natural pores remaining. On many of the internal surfaces imaged, there was the presence of sediment, specifically within the trabeculae of the bone.

Fig. 2. The general appearance of the morphological features present on the archaeological bones. 
The pathological bone exhibited the natural pores of the unmodified bones in addition to pores resulting from the increased bone activity associated with the increased osteoblastic activity (Fig.3). The nature of these pathology-related pores were in keeping with examples published elsewhere (e.g.: Ortner ${ }^{[14]}$, Roberts and Manchester ${ }^{[15]}$ Bridges $^{[19]}$ and Rogers ${ }^{[20]}$ ).

Fig. 3. The general appearance of the morphological features present on the pathological bones.

During the investigation of the burned bone, it was seen that the main morphological changes to the bone surface were attributed to cracking and pitting as can be seen in Fig. 4. The bone burned at a low intensity exhibited the cracked, rough surface and damaged pores associated with the commencement of heat-induced change. The bone burned at a higher intensity exhibited the smoother surface and redistributed pores indicative of the intense remodeling of bone at such temperatures, Both sets of change are in keeping with those heat-induced surface changes recorded elsewhere (such as Thompson ${ }^{[17,18]}$ ).

Fig. 4. The general appearance of the morphological features present on the burnt bones.

Measurements of the pores and abrasion marks were taken from all bone samples imaged following a random sampling strategy. Interestingly in both bombardment experiments, that is, exposure to a seawater and a freshwater environment, the sizes of the abrasion marks were found to correspond well to the grain size of the sand used in the investigation.

The sizes of the natural pores found on some of the archaeological bones were also measured. The majority of these pores were found to be of a larger size than the abrasion marks found on the bones submerged in an aquatic environment which exhibited the smallest variation in size. Furthermore, the size of the pits and pores found on the burnt bones were also measured. For the most part, these were found to be either larger or smaller than the abrasion marks, but tended to be smaller than those found on the pathological samples (Table 2). 
Table2. Pore size measurements for all the examined bone, mean values in bold with standard deviations.

During the morphological examination of the exposed bones, matter was observed on some of the bones. The SEM coupled with an energy dispersive $x$-ray spectrometer (SEM-EDX) was used to analyse the grainy matter for compositional identification. The analysis showed that the matter was mainly made up of silica (silicon and oxygen) which is the main constituent of sand. In the case of some of the modern bones subjected to a water environment, sand grains were found to be attached on the surface, whereas with the submerged archaeological bones the sand grains appeared to be stuck within the cracks present on their surface.

\section{Discussion}

From the results obtained, it was possible to carry out comparisons between the surface morphology of the bones which were subjected to bombardment in an aquatic environment to the remainder of the bones under investigation.

When comparing the bones subjected to a water environment to the dry comparative archaeological bones (non-pathological), it was evident that the submerged modern bones did not display many morphological similarities to the dry archaeological bones. The surface morphology of the dry archaeological bones appeared to be rather smooth, with minor cracking features. On the other hand, abrasion marks were the main features causing morphological change on the modern bones with no evidence of surface cracking.

In contrast, the submerged and dry archaeological bones displayed a distinct similarity in morphological appearance. Little morphological change was caused by the aquatic environment to the archaeological bones. Even though in general, the submerged archaeological bones displayed more cracking features on their morphology than the dry archaeological bones, this does not give rise to a distinct difference between these two sets of samples. Thus, it was still difficult to differentiate between the two. 
In light of this predicament, one possible way of differentiating between a submerged archaeological bone and a dry one would be to try and identify the presence of sediment. Buried bones in soil and silty environments tend to accumulate earth debris within cracks and their trabeculae matrix (Fig. 5). It is believed that this layer would be easily lost in highly energetic aquatic environments. On the other hand, archaeological bone exposed to a sandy beach environment will tend to accumulate sand grains within cracks present on their surfaces. As a result, identifying the presence of any of these two materials could help in determining the possible environment the bone would have been located in and this may be of significant help when examining isolated bones, as for example, are often taken to the police by members of the public.

Fig. 5. Mud present between the trabecular matrices of two dry archaeological bone samples.

A potential consideration when examining bones recovered from an aquatic environment is whether marks created by the mobile environment mimic those caused by pathological conditions. No similarities were noted in this study. Likewise there were no similarities between the marks left by sediment bombardment and heat-induced surface change. In addition, Fig. 6 demonstrates the good consistency between the sand grain size and abrasion mark size in the bombardment experiments. The sizes ranged from $187 \mu \mathrm{m}$ to $277 \mu \mathrm{m}$, with an average size approximately $200 \mu \mathrm{m}$, matching the bombardment material. As has been noted above, and in Thompson et al. ${ }^{[10]}$, this corresponds well with the abrasion marks left by their bombardment.

Fig. 6. Measurement of some sand grains present on one of the exposed modern bones.

Crucially, there are differences between the measurements of the natural pores and those created by burning or bombardment (Fig. 7).

Fig. 7. Measurements of abrasion marks present on the modern bones exposed to a seawater environment, the burnt bones and the 'natural' pores present on the archaeological bones.

Fig. 7 is a log graph which shows the general distribution of abrasion mark and pore size for the submerged and comparative samples. It can be seen that there is an 
overlap of abrasion/pore size between all these types of bones. In fact, these appear clustered. As stated previously, this means that the sediment bombardment on the exposed modern bones created abrasion marks which were of a similar size to the grain size, showing both accuracy and precision in data. In general, this size range was not frequently found for the pores on the archaeological bones and much less for the marks on the burnt bones. In fact, in terms of the pores found on the archaeological bones, they tended to be larger in size when compared to the abrasion marks found on the exposed bones. The high intensity burnt bones displayed the greatest range in pore size.

However, there are questions remaining regarding possible confusion occurring if the grain size from the sediment in the water was larger, smaller, or had a wider range than that used here. In these situations, the regularity of pore shape should be examined as this may well differ as a result of the cause of the osteological change, in addition to other surface features of the bone (for example, heat-induced colourchange in burned bone). Finally, as can be seen in Fig. 7, the range of pores sizes created by sediment bombardment is narrow compared to those occurring by other means used here. Nonetheless, further work is needed to examine this in more detail, with a particular focus on a narrower range of pore sizes.

\section{Conclusion}

From the comparisons carried out, several conclusions can be made. Similar abrasion marks were present on all the submerged bones. No similarities could be identified between the submerged modern bones and the dry archaeological bones. By contrast the submerged and dry archaeological bones are distinctly similar making it difficult to discriminate between the two. It is suggested that one possible way of differentiating between the two is to determine if sediment or sand grains are present on the bone. Sediment is easily lost in highly energetic environments whereas sand grains tend to accumulate within the cracks or on the surface of the bone in such aquatic environments. Furthermore, no similarities were found between marks created on the modern submerged bone to the ones created by the pathological conditions investigated in this study or with the heat-induced surface 
changes. Our preliminary study suggests that it is unlikely that the taphonomic history of isolated bones recovered from bodies of water would be misinterpreted in the forensic context. 


\section{References}

[1] Haglund WD, Sorg MH. Human remains in water environments. In: Haglund, WD, Sorg $\mathrm{MH}$, editors. Advances in Forensic Taphonomy: Method, Theory and Archaeological Perspectives. Florida: CRC Press; 2002, p. 201-18.

[2] Haglund WD. Disappearance of soft tissue and the disarticulation of human remains from aqueous environment. Journal of Forensic Sciences 1993;38(4):80615.

[3] Boyle S, Galloway A, Mason RT. Human aquatic taphonomy in the Monterey bay area. In: Haglund WD, Sorg MH, editors. Forensic Taphonomy: The postmortem fate of human remains, Florida: CRC Press; 1997, p. 605-13.

[4] Sorg MH, Dearborn JH, Monahan El, Ryan HF, Sweeney KG, David E. Forensic taphonomy in marine context. In: Haglund WD, Sorg $\mathrm{MH}$, editors. Forensic Taphonomy: The postmortem fate of human remains, Florida: CRC Press; 1997, p. 567-99.

[5] Dumser T, K. Turkay, M. Postmortem changes of human bodies on the Bathyal sea floor - Two cases of aircraft accidents above the open sea. Journal of Forensic Sciences 2008;53(5):1049-1052.

[6] Kahana T, Almog J, Levy J, Shmeltzer E, Spier Y, Hiss J. Marine taphonomy: adipocere formation in a series of bodies recovered from a single shipwreck. Journal of Forensic Sciences 1999;44(5):897-901.

[7] O'Brien TG, Kuehner AC. Waxing grave about adipocere: soft tissue change in an aquatic context. Journal of Forensic Sciences 2007;52(2):294-301.

[8]Ubelaker DH, Zarenko KM. Adipocere: What is known after over two centuries of research.Forensic Science International 2011;208:167-72. 
[9]Nawrocki SP, Pless JE, Hawley DA, Wagner SA. Fluvial transport of human crania.In: In: Haglund WD, Sorg MH, editors. Forensic Taphonomy: The postmortem fate of human remains, Florida: CRC Press; 1997, p. 529 - 52.

[10]Thompson CEL, Ball S, Thompson TJU, Gowland R. The abrasion of modern and archaeological bones by mobile sediments: the importance of transport modes. Journal of Archaeological Science 2011;38(4):784-93.

[11] Robinson RA. An electron-microscopic study of the crystalline inorganic component of bone and its relationship to the organic matrix. The Journal of Bone and Joint Surgery. American Volume 1952;34 A(2):389-435.

[12] Kuczumow A, Cukrowska E, Stachniuk A, Gaweda R, Mroczka R, Paszkowicz W, Skrzypiec K, Falkenberg R, Backwell L. Investigation of chemical changes in bone material from South African fossil hominid deposits. Journal of Archaeological Science 2010;37(1):107-15.

[13] Byers SN. Introduction to forensic anthropology. $3^{\text {rd }}$ ed. Boston: Pearson Education, Inc; 2005.

[14] Ortner DJ. Identification of pathological conditions in human skeletal remains. $2^{\text {nd }}$ ed. San Diego: Academic Press; 2003.

[15] Roberts CA, Manchester K. The archaeology of disease. 3rd ed. New York: Cornell University Press; 2007.

[16] MayneCorreia PM. Fire modification of bone: a review of the literature. In: In: Haglund WD, Sorg MH, editors. Forensic Taphonomy: The postmortem fate of human remains, Florida: CRC Press; 1997, p. 275-93.

[17] Thompson TJU. Recent advances in the study of burned bone and their implications for forensic anthropology. Forensic Science International 2004;146:2035. 
[18] Thompson TJU. Heat-induced dimensional changes in bone and their consequences for forensic anthropology.Journal of Forensic Sciences 2005;50:100815.

[19] Bridges PS. Prehistoric arthritis in the Americas. Annual Review of Anthropology 1992;21:67-91

[20] Rogers J. The palaeopathology of joint disease. In: Cox M, Mays S, editors. Human Osteology: In archaeology and Forensic Science, Cambridge: Cambridge University Press; 2000 pp 163-82. 


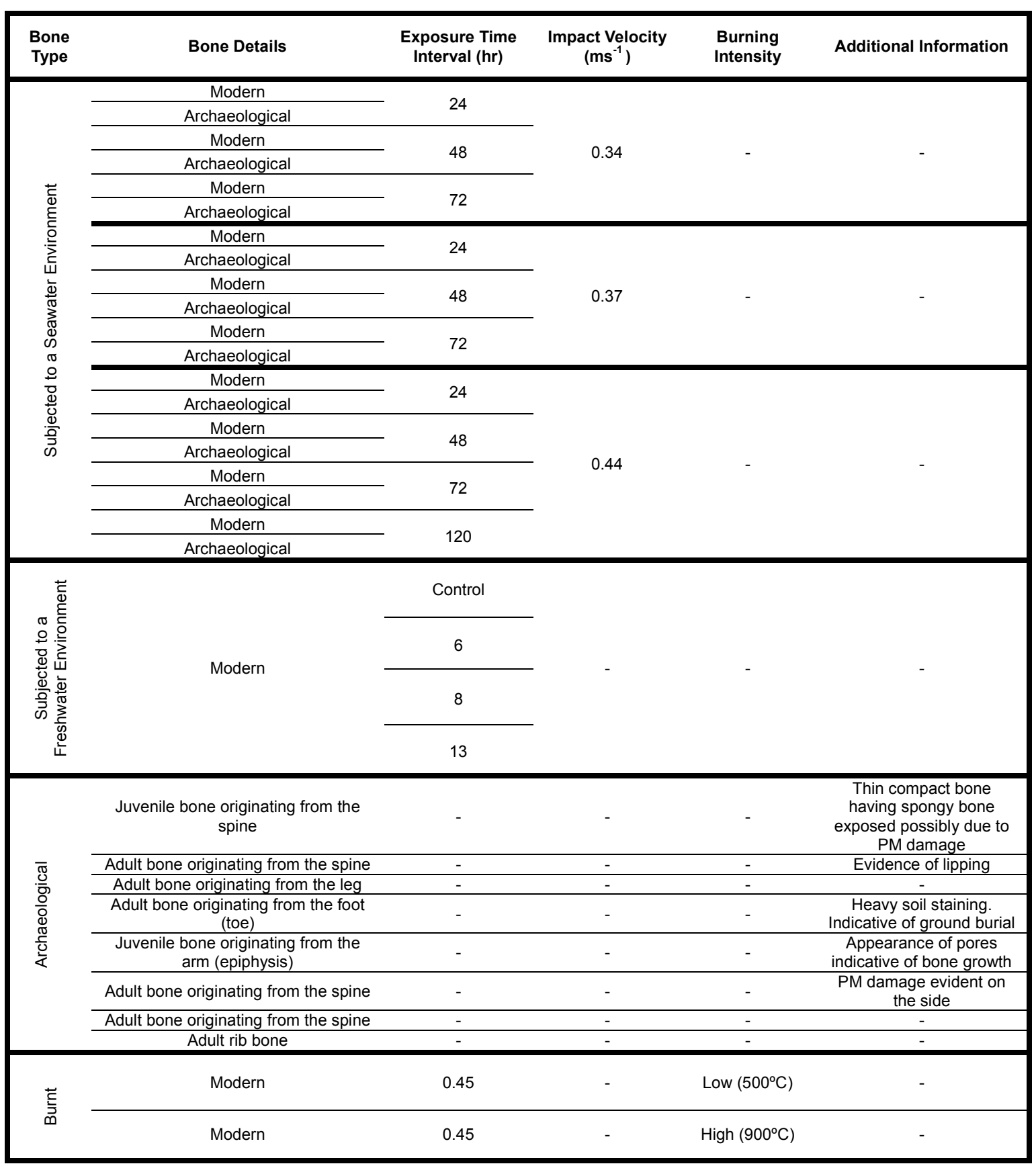




\begin{tabular}{|c|c|c|c|c|}
\hline \multicolumn{5}{|c|}{ Pore Size Measurements $(\mu \mathrm{m})$} \\
\hline $\begin{array}{c}\text { Abrasion } \\
\text { (Archaeological } \\
\text { and Modern) }\end{array}$ & $\begin{array}{c}\text { Weathering } \\
\text { (Archaeological) }\end{array}$ & $\begin{array}{c}\text { Pathological } \\
\text { (Archaeological) }\end{array}$ & $\begin{array}{l}\text { Low Intensity } \\
\text { Burning } \\
\text { (Modern) } \\
\end{array}$ & $\begin{array}{l}\text { High Intensity } \\
\text { Burning } \\
\text { (Modern) } \\
\end{array}$ \\
\hline 217 & 506 & 1620 & 37.6 & 1010 \\
\hline 266 & 338 & 595 & 26.7 & 905 \\
\hline 197 & 546 & 1370 & 39.4 & 390 \\
\hline 228 & 559 & 693 & 40.9 & 231 \\
\hline 277 & 278 & 249 & 155 & 145 \\
\hline 246 & 575 & 437 & 57.8 & 122 \\
\hline 194 & 1150 & 1020 & 96.6 & 124 \\
\hline 187 & 333 & 1280 & & 158 \\
\hline 266 & 99.2 & 519 & & 56.8 \\
\hline 276 & 335 & 403 & & 64 \\
\hline \multirow[t]{4}{*}{250} & 175 & 194 & & 64.6 \\
\hline & & 264 & & 56.1 \\
\hline & & 206 & & \\
\hline & & 167 & & \\
\hline $236.7 \pm 34$ & $444.9 \pm 282$ & $644.1 \pm 486$ & $64.9 \pm 46$ & $277.2 \pm 332$ \\
\hline
\end{tabular}




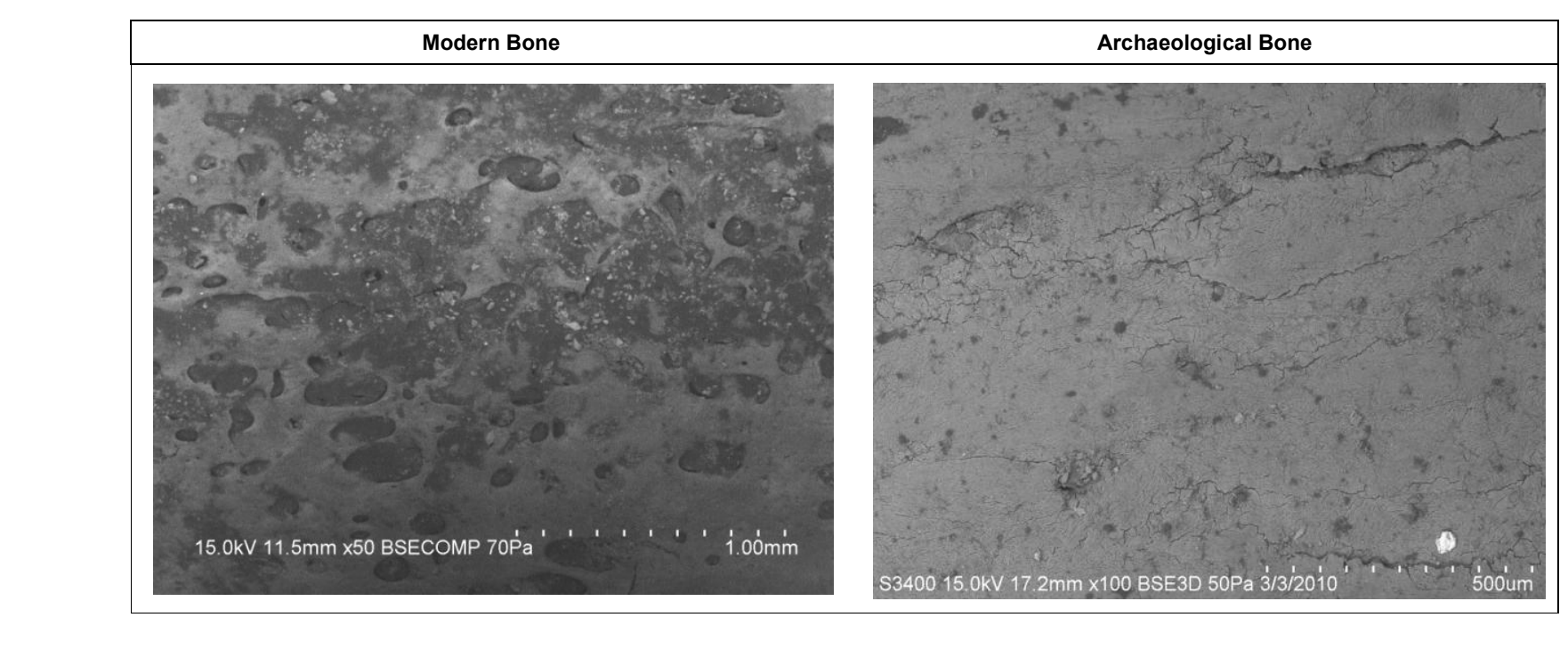

Figure(s)

\section{Figure(s)}

Modern Bon
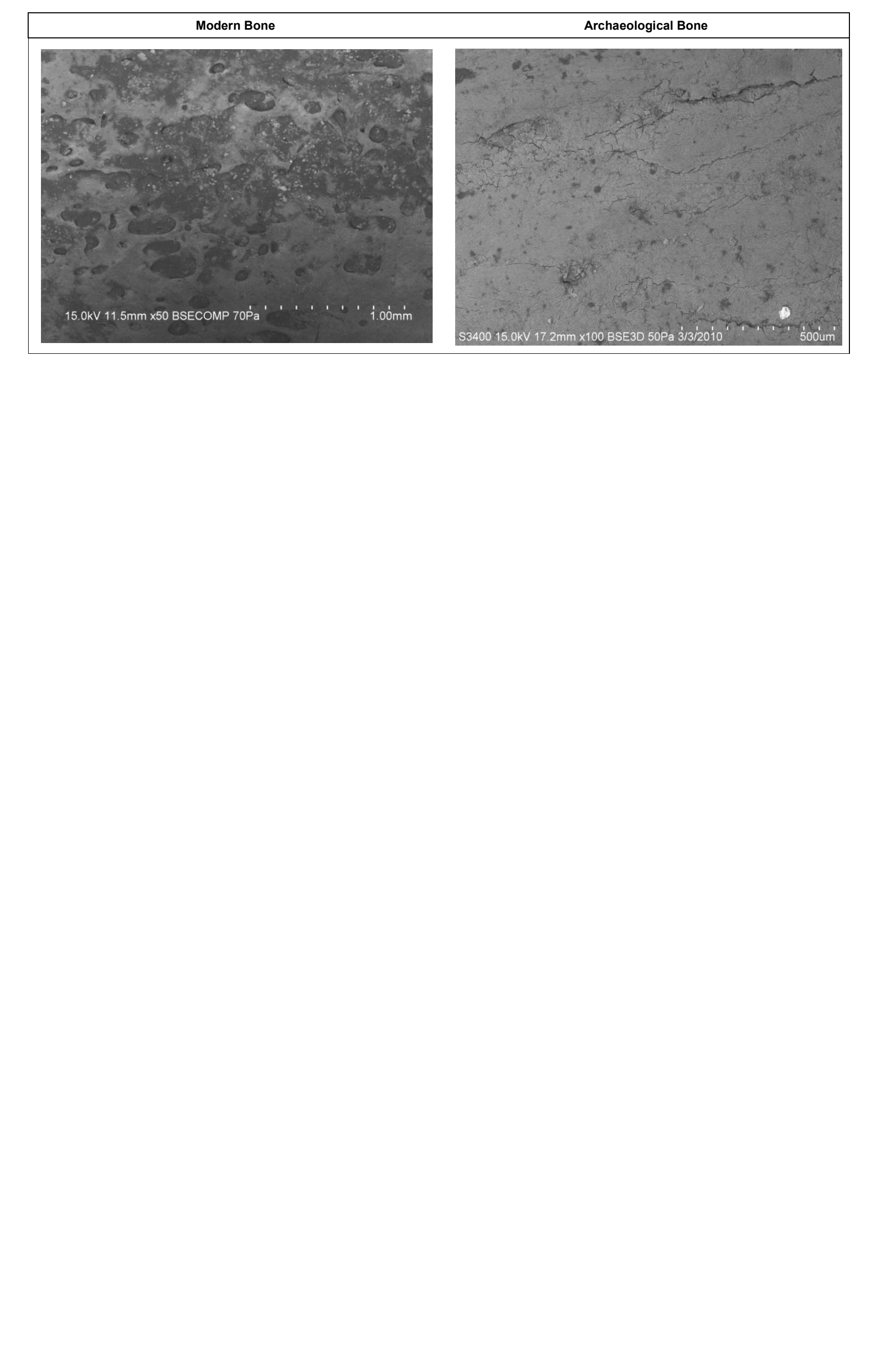

.

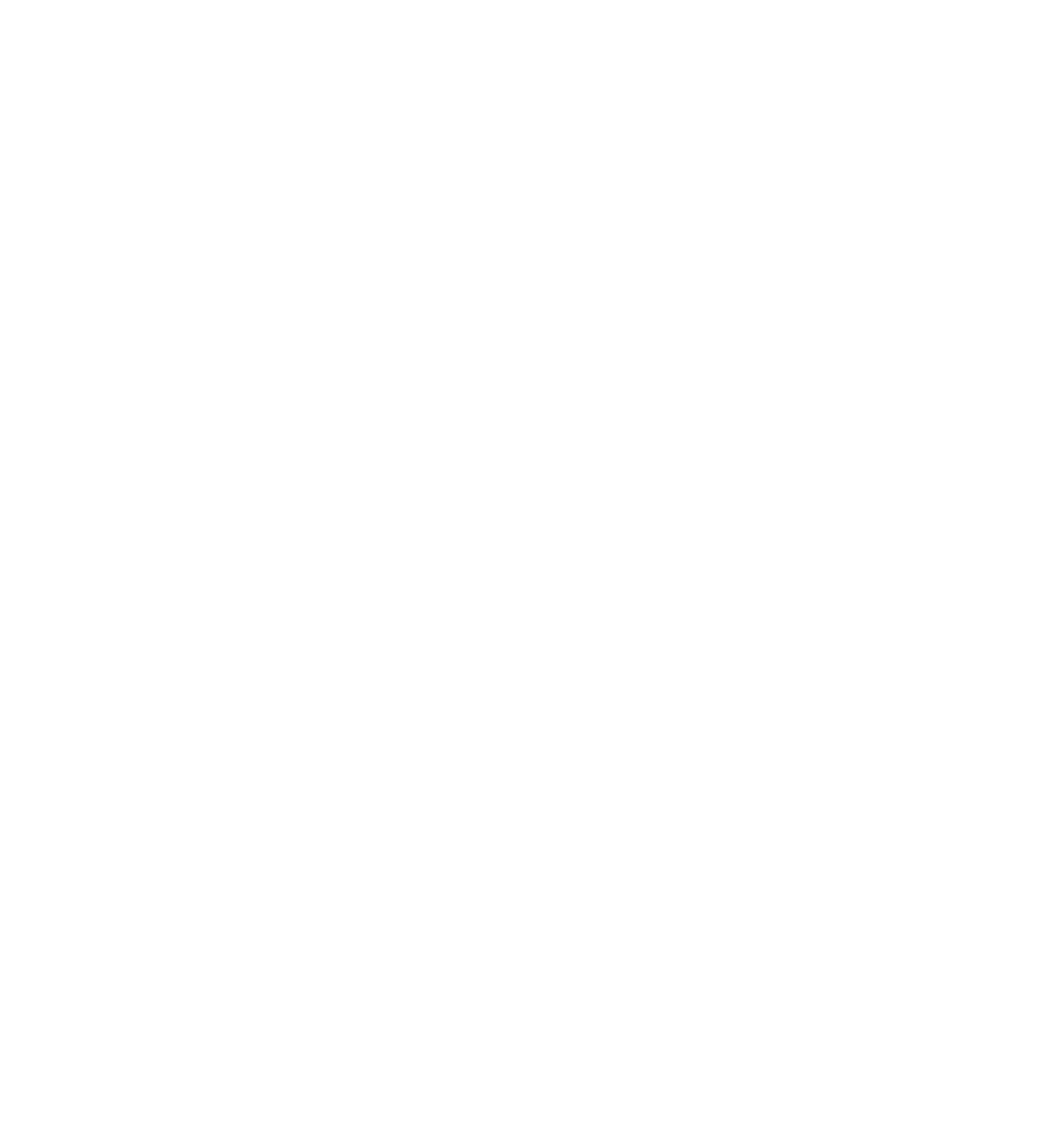
(⿸丆口

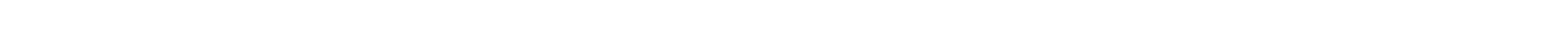

(
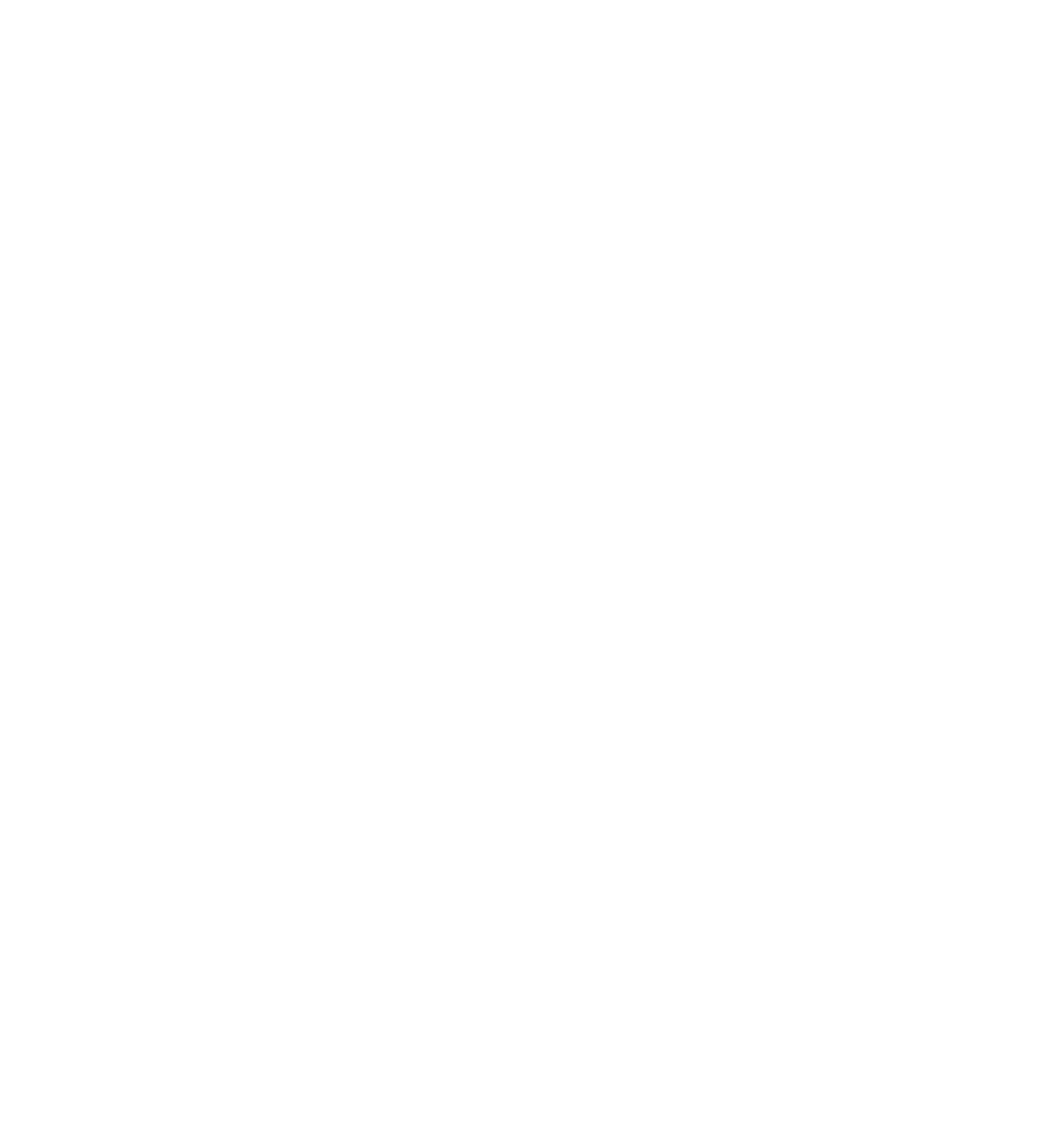
15.0kV 32.7mm x10 BSECOMP 50Pa 12/10/200́9 14:12 ' 5.00́mm

Figure(s)
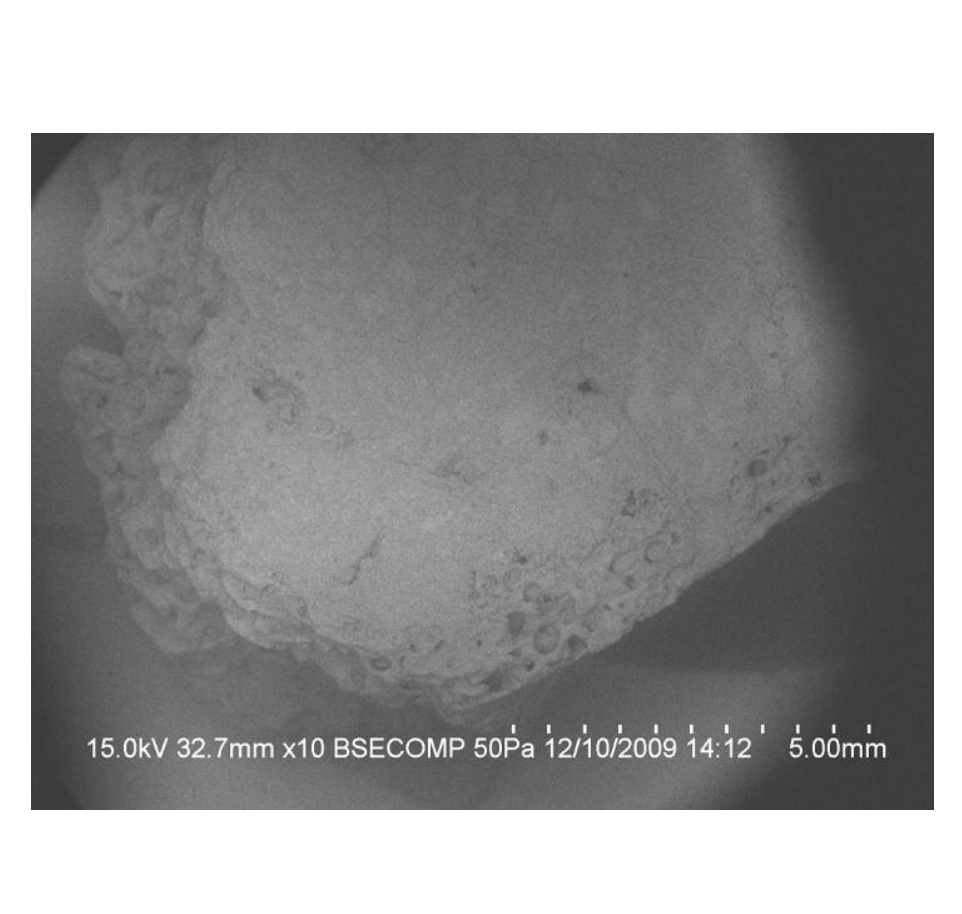

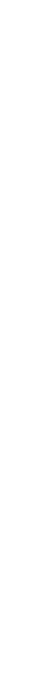

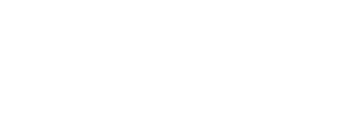

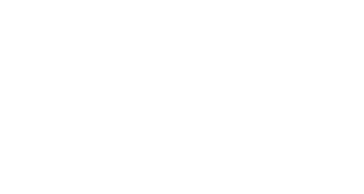

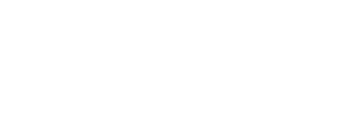

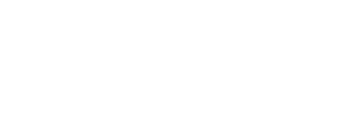

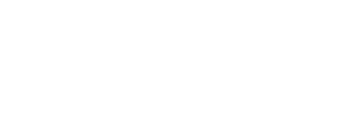




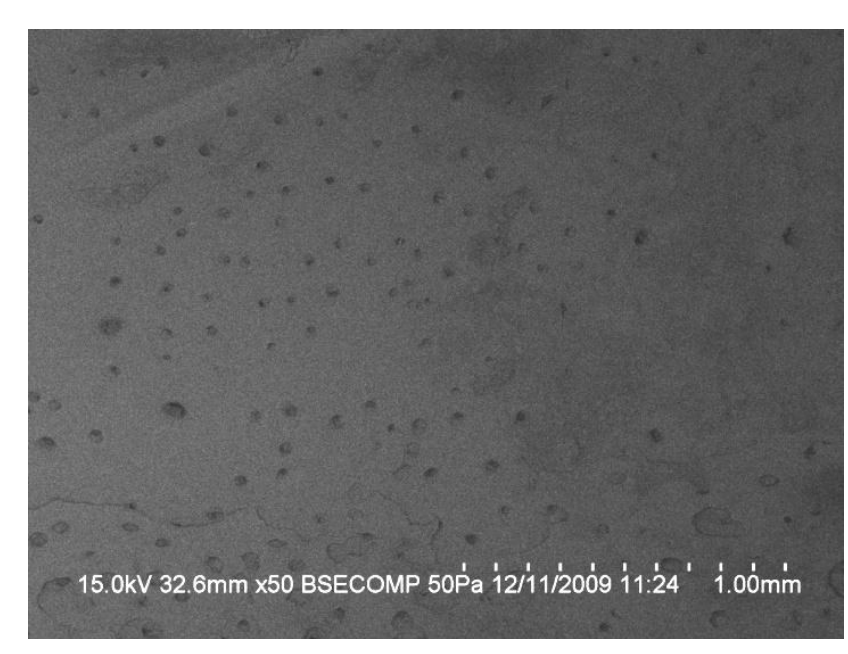

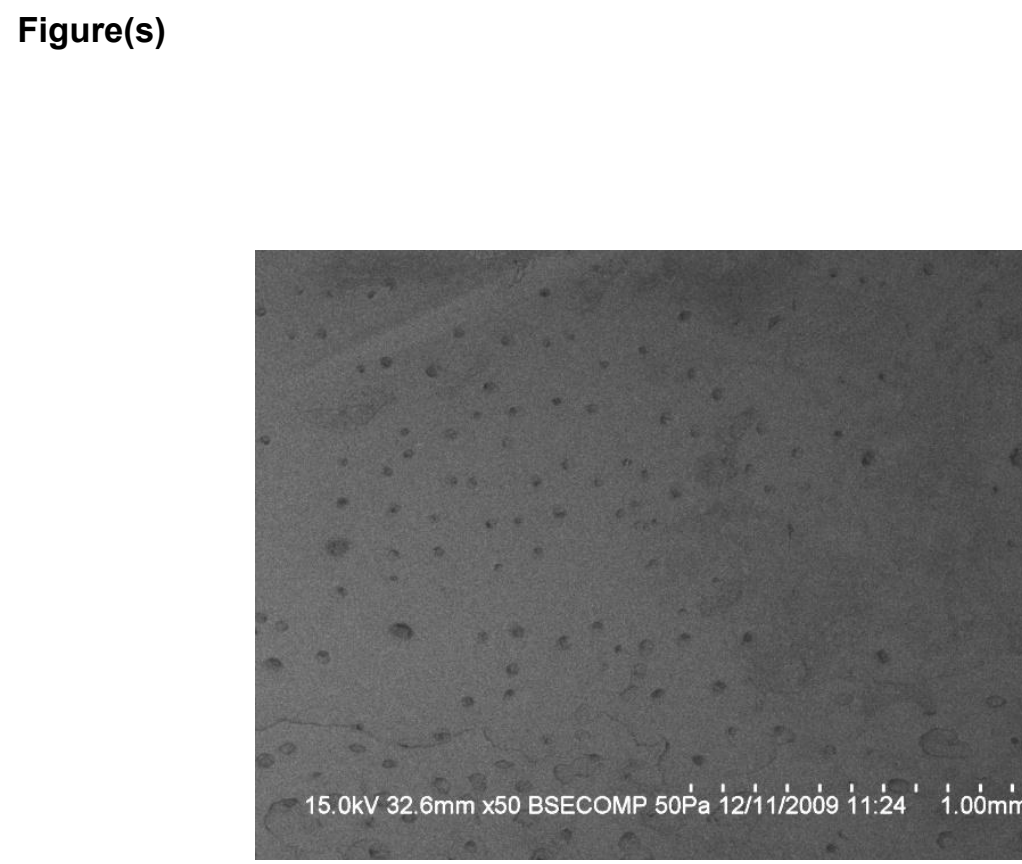
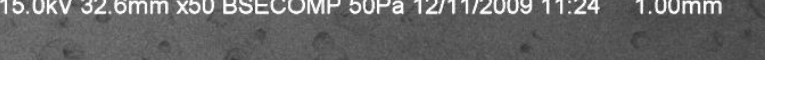


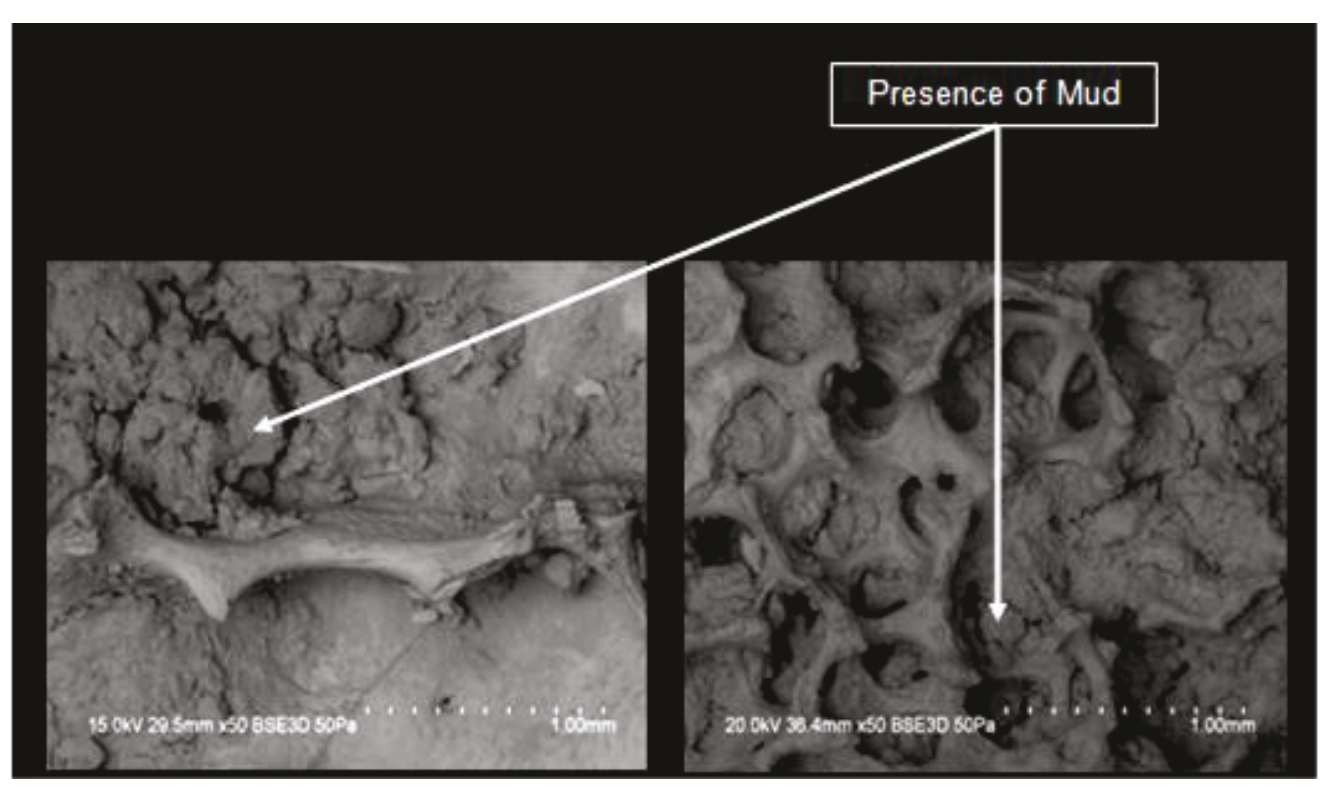

Figure(s) 


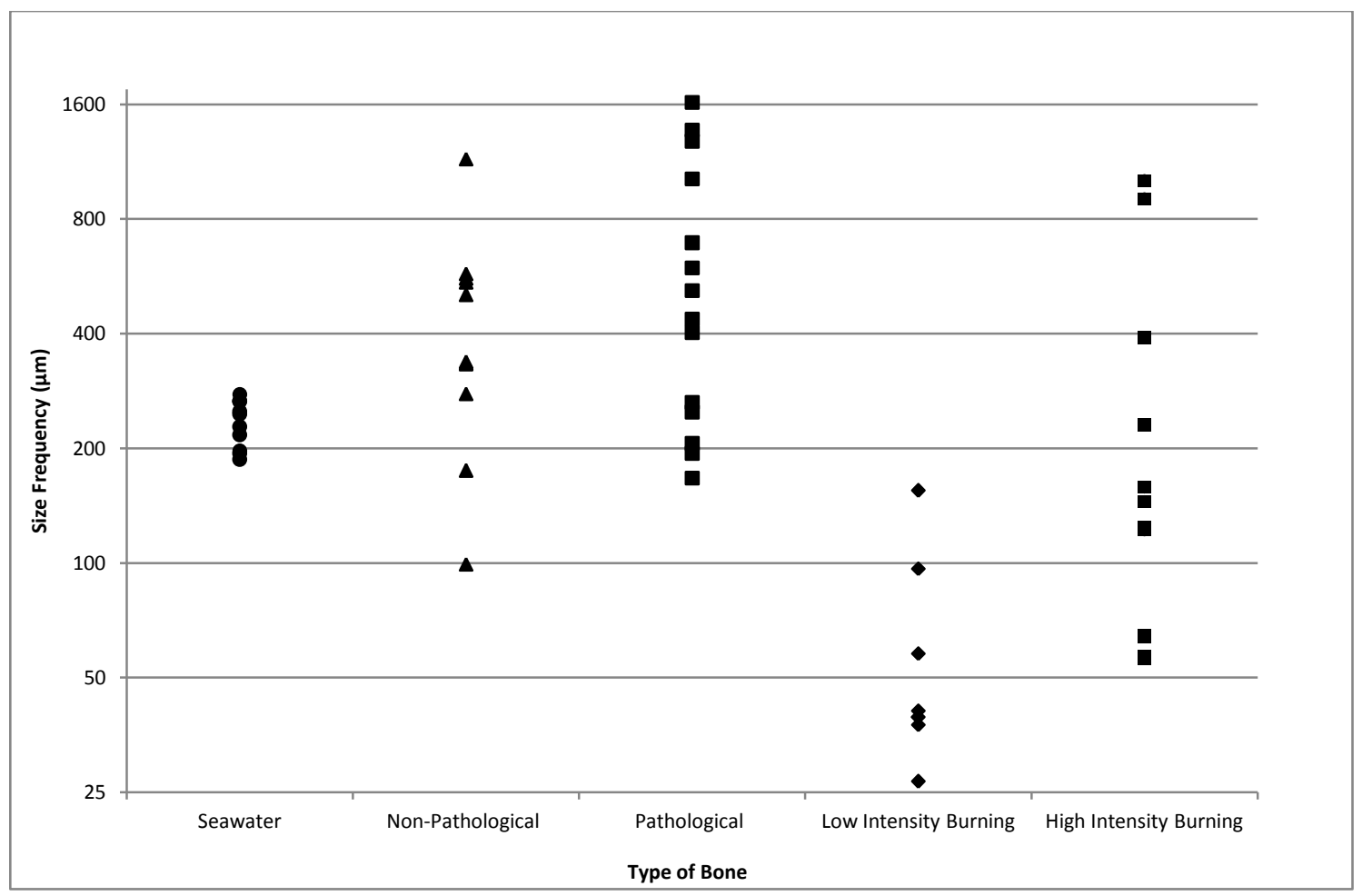




\begin{tabular}{|c|c|c|c|c|}
\hline \multirow{3}{*}{ Seawater } & & & Low & High \\
\hline & & & Intensity & Intensity \\
\hline & Non-Pathological & Pathological & Burning & Burning \\
\hline 217 & 506 & 1620 & 37.6 & 1010 \\
\hline 266 & 338 & 595 & 26.7 & 905 \\
\hline 197 & 546 & 1370 & 39.4 & 390 \\
\hline 228 & 559 & 693 & 40.9 & 231 \\
\hline 277 & 278 & 249 & 155 & 145 \\
\hline 246 & 575 & 437 & 57.8 & 122 \\
\hline 194 & 1150 & 1020 & 96.6 & 124 \\
\hline 187 & 333 & 1280 & & 158 \\
\hline 266 & 99.2 & 519 & & 56.8 \\
\hline 276 & 335 & 403 & & 64 \\
\hline \multirow[t]{8}{*}{250} & 175 & 194 & & 64.6 \\
\hline & & 264 & & 56.1 \\
\hline & & 206 & & \\
\hline & & 167 & & \\
\hline & & & & mean \\
\hline & & & 64.85714 & 277.2083 \\
\hline & & & & stdev \\
\hline & & & 45.83317 & 332.1205 \\
\hline
\end{tabular}

